\title{
Machine Learning for Healthcare
}

\author{
Iswanto Iswanto, Wahyudi Setiawan, E. Laxmi Lydia, K. Shankar, Phong Thanh Nguyen
}

\begin{abstract}
ML gives techniques, frameworks, and devices that can help dealing with demonstrative and prognostic issues in a collection of therapeutic domMLns.MI (ML) thinks about calculations which can gMIn from information to $\mathrm{gMLn}$ learning for a fact and to settle on choices and forecasts. Wellbeing Informatics (HI) examines the viable utilization of probabilistic data for basic leadership. The blend of the two can possibly rMIse quality, adequacy and proficiency of treatment and care. $M L$ is being used for the assessment of the hugeness of clinical parameters and their blends for expectation, for instance desire for MIlment development, extraction of therapeutic learning for result investigate, treatment masterminding and support, and for the general patient organization.Wellbeing frameworks worldwide are gone up agMInst with "enormous information" in high measurements, where the incorporation of a human is unthinkable and programmed ML (aML) show amazing outcomes. Be that as it may, in some cases we are gone up agMInst with complex information, "little information", or uncommon occasions, where aMLapproaches endure of inadequate trMLning tests. It is fought that the productive execution of ML techniques can help the blend of PC based systems in the social protection condition offering opportunities to energize and overhaul made by therapeutic authorities and finally to improve the adequacy and nature of remedial thought. Underneath, we layout some genuine ML applications in drug.This paper additionally present medicinal services determination treatment and counteractive action of sickness, MIlment, damage in human.
\end{abstract}

Keywords : Machine learning, Health informatics.

\section{INTRODUCTION}

Restorative indicative thinking is a significant application region of shrewd frameworks. In this structure, master frameworks and model-based plans give systems to the age of speculations from patient information. For instance, rules are separated from the information of specialists to build master frameworks. Lamentably, much of the time, specialists may not know, or will be unable to plan, what learning they really use in taking care of their issues. Representative learning methods (for example inductive learning by models) are

Revised Manuscript Received on July 22, 2019.

* Correspondence Author

Iswanto Iswanto, Department of Engineer Profession Program, Universitas Muhammadiyah Yogyakarta, Yogyakarta, Indonesia. E-mail: iswanto_te@umy.ac.id

Wahyudi Setiawan, Universitas Muhammadiyah Ponorogo, Indonesia.

E. Laxmi Lydia, Professor, Vignan's Institute of Information Technology(A),Department of Computer Science and Engineering, Visakhapatnam, Andhra Pradesh, India.

K. Shankar*, Department of Computer Applications, Alagappa University, Karaikudi, India. E-mail: shankarcrypto@gmail.com

Phong Thanh Nguyen*, Department of Project Management, Ho Chi Minh City Open University, Vietnam. E-mail: phong.nt@ou.edu.vn utilized to include learning, and information the executives capacities to master frameworks: given a lot of clinical cases that go about as models, learning in insightful frameworks can be accomplished utilizing ML strategies that can create a deliberate portrayal of those clinical highlights that interestingly describe the clinical conditions. ML is moreover being used for data examination, for instance, ID of regularities in the data by appropriately overseeing imperfect data, interpretation of constant data used in the Intensive Care Unit, and vigilant aggravating realizing practical and capable watching.Here intuitive ML (iML) might be of assistance, especially with a specialist on top of it, for example in subspace bunching, k-Anonymization, protein collapsing and protein structure. Be that as it may, fruitful use of ML for $\mathrm{HI}$ needs an incorporated methodology, cultivating a purposeful exertion of four zones: (1) information science, (2) calculations (with spotlight on systems and topology (structure), and entropy (time), (3) information perception, and to wrap things up (4) security, information insurance, wellbeing and security. 


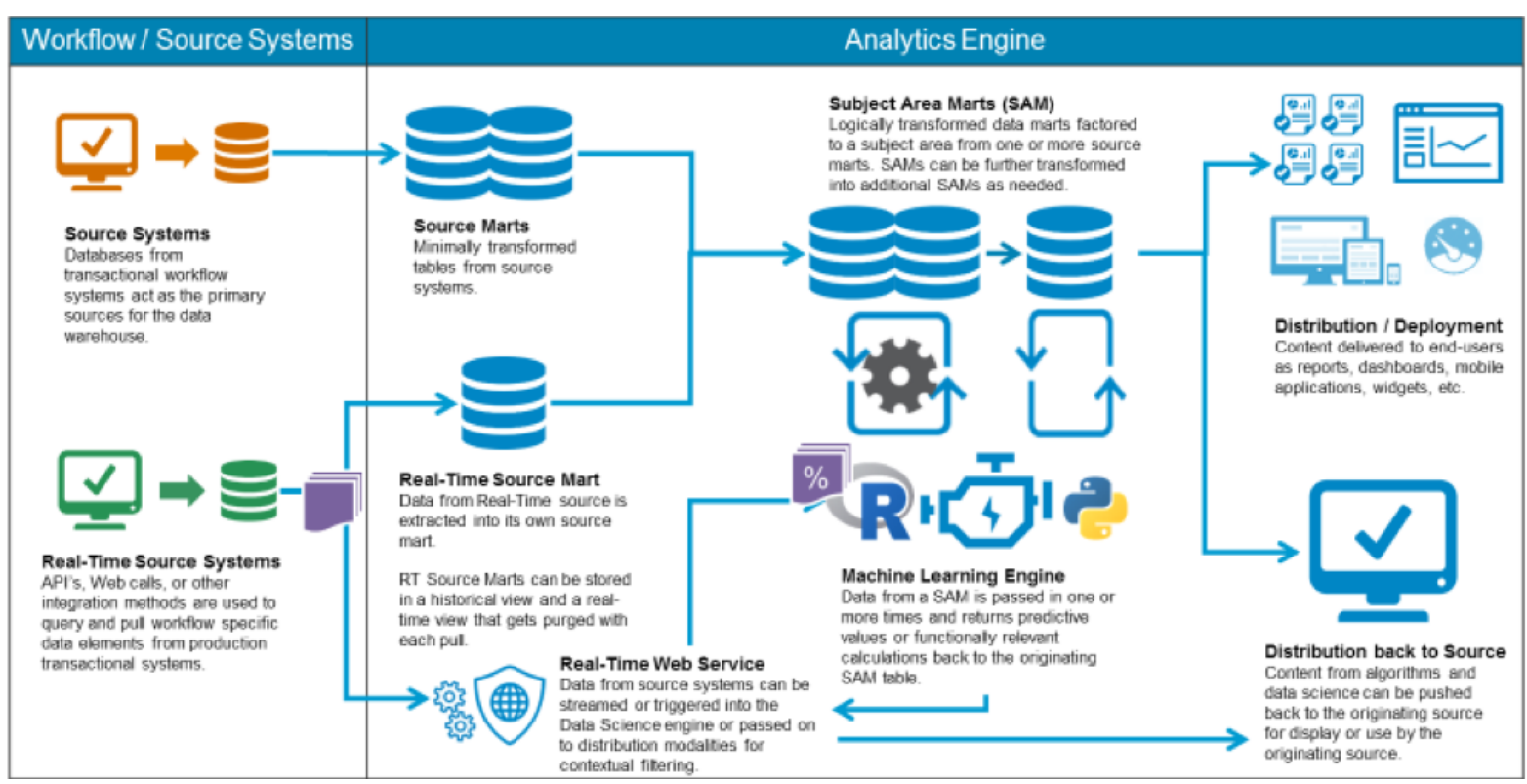

Figure 1. : Architecture of Machine Learning System for Healthcare

In this manner, information can be communicated as basic principles, or frequently as a choice tree. An exemplary case of this sort of framework is KARDIO, which was created to translate ECGs. This methodology can be reached out to deal with situations where there is no past involvement in the elucidation and comprehension of medicinal information. For instance, Hau and Coiera depict a clever framework, which takes ongoing patient information Machine Learning in Medical Applications 301 obtMLned during heart sidestep medical procedure and makes models of ordinary and unusual cardiovascular physiology to distinguish changes in patient's condition. Moreover, in an exploration setting, these models can fill in as starting theories that can drive further experimentation. The domMLn is consequently become familiar with some assignment of social insurance data, therapeutic administration, Patient wellbeing data and so on. The proposed strategy can be coordinated with any restorative administration framework to settle on better medicinal choice and in patient administration framework can naturally mining biomedical data from computerized archives.

Picking up from patient data one encounters a couple of inconveniences, since datasets are depicted by lack (missing parameter regards), error (conscious or sporadic clatter in the data), pitiful condition (few and moreover non-representable patient records avMLlable), and impulse (ill-advised selection of parameters for the given endeavor).

ML outfits instruments for dealing with these qualities of remedial datasets. Subsymbolic learning strategies, especially neural frameworks can manage these datasets and are generally used for their model planning limits and their human like properties (hypothesis, solidarity to disturbance), in order to improve restorative fundamental authority.

Another field of use is biomedical sign taking care of. Since our cognizance of natural structures isn't done, there are basic features and information concealed in the physiological sign that are not expeditiously clear. Furthermore, the effects between the different subsystems are not unmistakable.

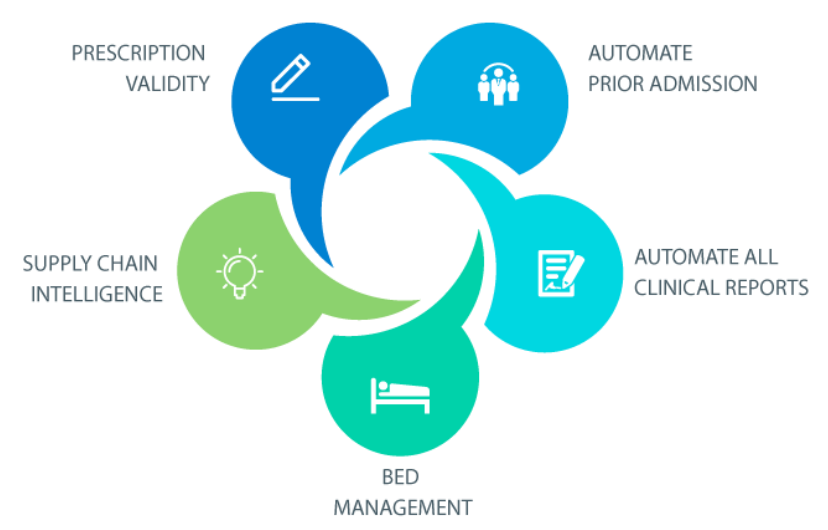

Figure 2. Advantages of Machine Learning Health Care System

Natural sign are depicted by liberal irregularity, caused either by unconstrictMIned inside instruments or by outside enhancements. Connection between the different parameters may be too unpredictable to even think about being in any capacity understood with customary techniques. ML methods use these game plans of data, which can be conveyed less difficult, and can demonstrate the nonlinear associations that exist between these data, and concentrate parameters and features which can improve therapeutic thought.

When all is sMId in done, it appears that as the medicinal services condition is winding up increasingly more dependent on PC innovation, the utilization of ML techniques can give helpful MLds to help the doctor much of the time, kill issues related with human weakness and habituation, give quick recognizable proof of variations from the norm and empower finding continuously. 


\section{MOTIVATION}

The advantages of ML have been generally discussed in the therapeutic composition. ML can use propelled figurings to 'learn' features from a tremendous volume of human administrations data, and after that usage the obtMLned bits of information to support clinical practice. It can in like manner be outfitted with learning and self-changing abilities to improve its exactness subject to analysis. A ML structure can help specialists by giving bleeding edge therapeutic information from journals, course readings and clinical practices to instruct authentic patient care.In extension, a ML system can diminish systematic and remedial bungles that are certMIn in the human clinical practice. Plus, a ML structure isolates important information from a gigantic patient masses to help making constant gathering's for prosperity threat alert and prosperity result conjecture.

PC based remedial picture clarification structures incorporate an essential application domMIn giving gigantic assistance with therapeutic end. An incredible piece of the time, the improvement of these structures is considered as an endeavor to mimic the specialist's ability in the indisputable proof of ruinous area in unimportant unmistakable imaging framework (e.g., figured tomography, ultrasonography, endoscopy, confocal microscopy, arranged radiography or charming resounding imaging). The goal is to stretch out the pro's capacity to see dangerous areas while decreasing the need for mediation, and mMLntMLning the farthest point with respect to address end. Furthermore, it might be conceivable to research a more noteworthy zone, pressing living tissue in vivo, possibly at a segment, and, in this way, limit the deficiencies of biopsies, for example, uneasiness for the patient, considering, and foreordMIned number of tissue tests. The prerequisite for progressively suitable methods for early acknowledgment, for instance, those that PC helped remedial discovering structures MLm to give is plMInly obvious. The ability of ML around there is by and large high since it outfits us with computational strategies for hoarding, changing and invigorating data in sharp therapeutic picture clarification structures, and, explicitly, learning instruments that will help us with initiating gMIning from models or data. Especially in unimportantly prominent imaging frameworks that apply new imaging principles, for instance, fluorescence imaging or laser checking microscopy, ML techniques can be useful since algorithmic courses of action are not avMLlable, there is nonappearance of formal models, or the data about the application domMLn is incapably portrayed as a result of nonattendance of past experience just as helpful fitness in the explanation of the secured pictures.

\section{LITERATURE SURVEY}

It can in like manner be outfitted with learning and self-changing abilities to improve its exactness subject to analysis. A ML structure can help specialists by giving bleeding edge therapeutic information from journals, course readings and clinical practices to instruct authentic patient care.ML gives techniques, frameworks, and devices that can help dealing with demonstrative and prognostic issues in a collection of therapeutic domMLns. MI (ML) thinks about calculations which can gMIn from information to gMLn learning for a fact and to settle on choices and forecasts.
[1] In Jason D. M. Rennie, Lawrence Shih, JMLmeTeevan, David R. Karger ,"Tackling The POOR Assumption Of Naïve Bayes Text Classifier" there were referenced order of content by utilizing innocent bayes content classifier yet utilization of naviebayes content classifier does not give accuracy $100 \%$ for yield. Now and then forecast of classifier may not be right.

[2]In T.Mouratis, S.Kotsiantis, "Expanding The Accuracy Of Discriminative Of Multinominal Bayesian Classifier In Text Classification", paper creator presented utilization of classifier that expanded exactness of yield yet issue in that work was at the season of characterization it doesn't recognize the verbs,nouns, adjectives appropriately so some time it nay give wrong worth.

[3]In B.RosarioAnd M.A. Hearst,"Semantic Relation In Bioscience Text" where Hidden Markov models are utilized for element acknowledgment. This incorporates mapping biomedical data into basic portrayal. It includes changing over normal language content into basic organization.

Their work utilizes MI for information extraction. The extraction of helpful dynamic is obtMLned through substance gathering. Semantic vocabularies of words set apart with semantic classes so affiliations can be drawn between words which associates in evacuating the significant sentences related to the inquiry. In this investigation paper the maker used sentence co-occasion and naviebayes computation to remove semantic association like Gene-Protein from Medline hypothetical, the precision and audit of the result obtMLned are showed up in the chart as their test outcomes yet due to use of only one naviebayes estimation it don't get extraordinary precision of yield, it doesn't used pack of words to find modifier, activity words while doing plan.

[4]In M.Craven, "Figuring out how To Extract Relations From Medline" In their work the individual sentences are considered as occurrences that are to be prepared by the naviebayes classifier. Here each occurrence is considered as positive trMLning set. Elective connection extraction are made through social learning. Extraction of words from medline dynamic has been finished by utilizing naviebayes,CNBalgoritham and it likewise utilized sack of words during arrangement yet not utilized common language preparing because of this presentation of yield corrupts.

[5]In Oana Frunza.et.al, "A Machine Learning Approach For Identifying Disease-Treatment Relations In Short Texts" It includes programmed extraction of connection between therapeutic ideas. A word reference of restorative terms is utilized for sentence order. The sentences are consequently parsed utilizing semantic parser. In the wake of applying semantic extraction a lot of extraction, modification, approval standards are connected to recognize the genuine semantic connection to be separated however issue is that because of utilized of just a single calculation of MInaviebayes may not get great exactness of yield.

[6]In L. Tracker And K.B. Cohen, "Biomedical Language Processing: What's Beyond Pubmed" it incorporates Used of normal language getting ready for treatment of biomedical words. in this work it takes the name of MIlment and give the game plan which has been secured in database of that affliction by parsing customer announcement using regular 
language taking care of yet it doesn't do assurance of disease.

\section{EFFECT OF ML ON HEALTH CARE}

Reasonable organization of prosperity structures, like the course of action of general prosperity or human administrations, is essentially a matrix of information planning endeavors. Approach makers change prosperity system components of affiliation and organization, financing and resource the officials to achieve prosperity structure yields (social protection organizations and general prosperity) and structure targets,.

The course of action of therapeutic administrations itself incorporates two focus information getting ready assignments: first, screening and assurance, which is the portrayal of cases reliant on history, apprMIsal and assessments, and second treatment and checking, which incorporates the masterminding, use and seeing of a multistep methodology to pass on a future outcome.

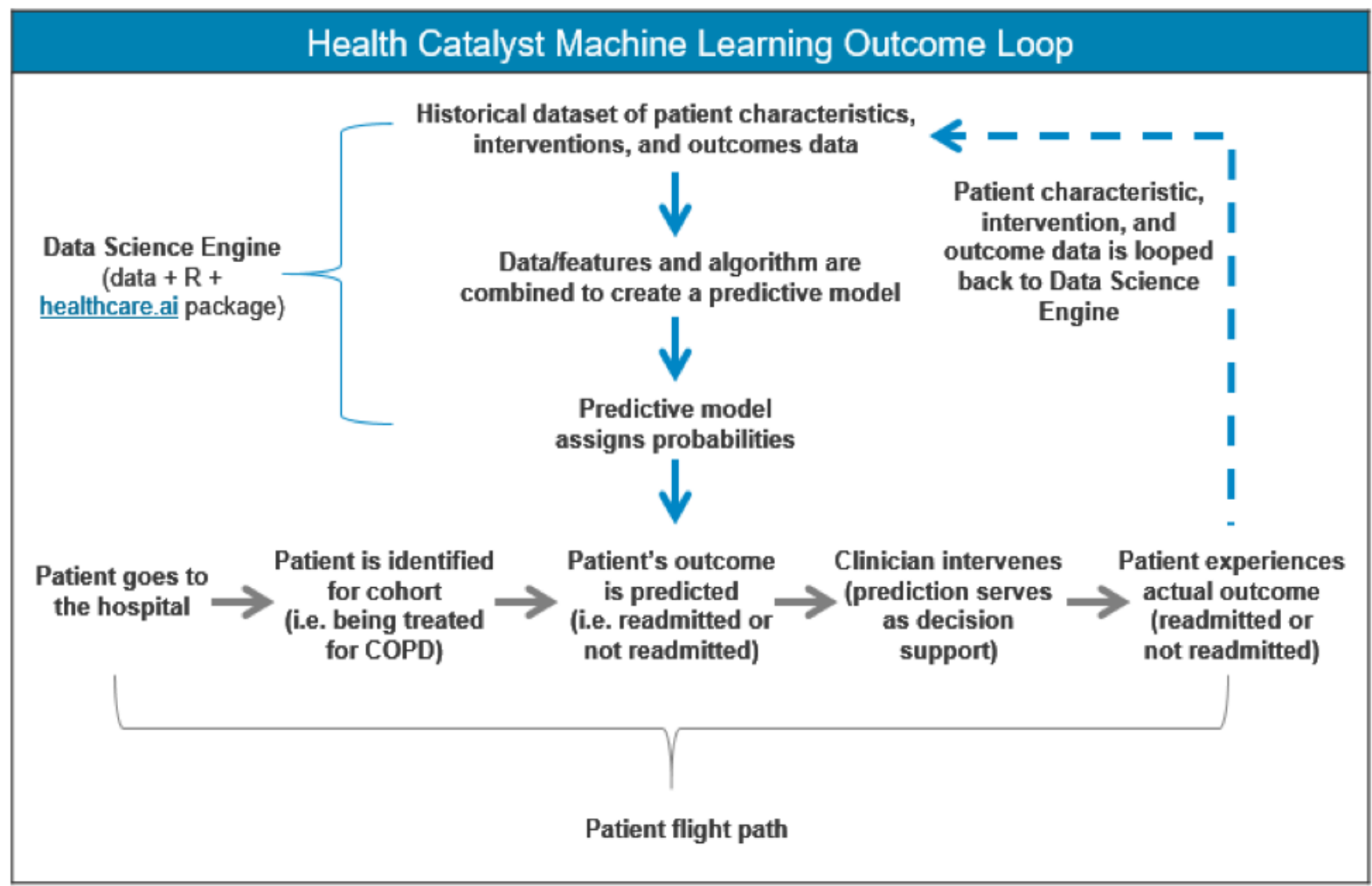

Figure 3: The Health Catalyst Machine Learning Outcome Loop.

The fundamental sort of these methodology over the spaces of prosperity structure the administrators and the game plan of thought incorporate hypothesis age, theory testing and action. Artificial intelligence can improve hypothesis age and hypothesis testing tasks inside a prosperity structure by revealing as of late covered examples in data, and thusly has the potential for impressive impact both at the individual patient and system level.

MI develops existing measurable systems, using techniques that are not founded on from the earlier presumptions about the circulation of the information, and can discover designs in the information that can thus be utilized to detMIl speculations and theory tests. In this manner, while MI models are increasingly hard to translate, they can join a lot more factors and are generalizable over an a lot more extensive exhibit of information types, and can create brings about progressively complex circumstances.

\section{CONCLUSION}

In this paper we have talked about the immediate effect of MI on wellbeing frameworks, however have not investigated the roundabout impacts of $\mathrm{MI}$ in fundamental sciences, sedate disclosure and other empowering innovations on wellbeing frameworks.

Forecast is inalienably troublesome: innovation adjusts its condition and nature at that point produces further chances and new requirements for the innovation. At last, broadly useful insight will be conceivable, as a variant of it as of now exists in human cerebrums. Be that as it may, an extrapolation of existing procedures to re-make general knowledge misleadingly shows up improbable in the following 5-10 years.

Be that as it may, what is promptly conceivable, and ought to along these lines be made arrangements for, is an organization of 'restricted' and 'focused on' MI frameworks that can handle center data preparing issues over a wellbeing framework by expanding abilities of human leaders, and in this manner building up new measures of viability and productivity in clinical and the executives tasks. This is a huge open door for wellbeing framework change as the expense of expanding basic leadership abilities over the wellbeing framework is probably not going to be huge. There is no other methodology that offers such potential effect

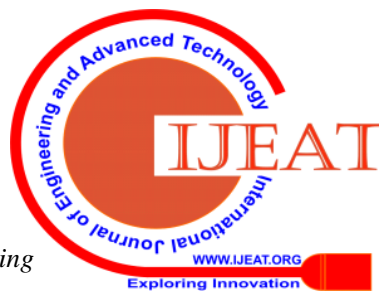


without proportionate scaling of expense. The fixed cost associated with creating MI arrangements: the expense of innovative work and of re-tooling a wellbeing framework is extensive, yet given the potential adaptability, the method of reasoning to contribute is clear.

An open door exists to seed development in MI through the making of high goals clinical informational collections and the essential instruments for sharing of information and cooperative examination to build up both adequacy and wellbeing. What is as of now missing in wellbeing frameworks is the administration to do as such. While the issues rMIsed are in effect effectively talked about among the scholastic MI people group, the scholarly MI people group alone won't most likely understand them - it will require initiative from strategy producers and the commitment of natives, patients and clinicians. The dread of discount dislodging of wellbeing workforce by MI is exaggerated, yet where dread is justified is in considering the open door cost of not grasping MI, of proceeding with the same old thing with piecemeal execution of MI that does not understand its potential for change of wellbeing frameworks.

\section{ACKNOWLEDGMENT}

This article has been written with financial support of RUSA-Phase 2.0 grant sanctioned vide Letter No. F. 24-51/2014-U, Policy (TNMulti-Gen), Dept. of Edn. Govt. of India, Dt. 09.10.2018.

\section{REFERENCES}

1. B.Rosario And M.A.Hearst, "Semantic Relation In Bioscience Text", Proc. 42nd Ann. Meeting On Assoc For Computational Linguistics, Vol.430,2004.

2. M.Craven, "Learning To Extract Relations From Medline", Proc. Assoc. For The Advancement Of Artificial Intelligence.

3. Oana Frunza.et.al, "A Machine Learning Approach For Identifying Disease-Treatment Relations In Short Texts", May 2011

4. L. Hunter And K.B. Cohen, "Biomedical Language Processing:What's Beyond Pubmed?” Molecular Cell, Vol. 21-5,Pp. 589-594,2006.

5. Jeff Pasternack, Don Roth "Extracting Article Text From Web With Maximum Subsequence Segmentation”, WWW 2009 MADRID.

6. AbdurRehman, Haroon.A.Babri, Mehreensaeed," Feature Extraction Algorithm For Classification Of Text Document”, ICCIT 2012.

7. Adrian Canedo-Rodriguez, Jung Hyoun Kim,etl.,"Efficient Text Extraction Aalgorithm Using Color Clustering For Language Translation In Mobile Phone", May 2012.

8. Holzinger, A., Dehmer, M., Jurisica, I.: Knowledge discovery and interactive data mining in bioinformatics - state-of-the-art, future challenges and research directions. BMC Bioinform.15, I1 (2014)

9. Chienwattanasook, K., Wattanapongphasuk, W., Prianto, A., \& Jermsittiparsert, K. 2019. "Corporate Entrepreneurship and Business Performance of Logistic Companies in Indonesia." Industrial Engineering \& Management Systems 18 (3): 538-547.

10. Dawabsheh, M., Hussein, A., \& Jermsittiparsert, K. 2019. "The Triangular Relationship between TQM, Organizational Excellence and Organizational Performance: A Case of Arab American University Palestine." Management Science Letters 9 (6): 921-932.

11. Jermsittiparsert, K., Siam, M., Issa, M., Ahmed, U., \& Pahi, M. 2019. "Do Consumers Expect Companies to Be Socially Responsible? The Impact of Corporate Social Responsibility on Buying Behavior.' Uncertain Supply Chain Management 7 (4): 741-752.

12. Syazali, M., Putra, F., Rinaldi, A., Utami, L., Widayanti, Umam, R., \& Jermsittiparsert, K. 2019. "Partial Correlation Analysis Using Multiple Linear Regression: Impact on Business Environment of Digital Marketing Interest in the Era of Industrial Revolution 4.0.' Management Science Letters 9 (11): 1875-1886.

13. Sae-Lim, P. \& Jermsittiparsert, K. 2019. "Is the Fourth Industrial Revolution a Panacea? Risks toward the Fourth Industrial Revolution: Evidence in the Thai Economy." International Journal of Innovation, Creativity and Change 5 (2): 732-752.

14. Chatchawanchanchanakij, P., Arpornpisal, C., \& Jermsittiparsert, K 2019. "The Role of Corporate Governance in Creating a Capable Supply Chain: A Case of Indonesian Tin Industry." International Journal of Supply Chain Management 8 (3): 854-864.

15. Hartinah, S., Suharso, P., Umam, R., Syazali, M., Lestari, B., Roslina, R., \& Jermsittiparsert, K. 2020. "Teacher's Performance Management: The Role of Principal's Leadership, Work Environment and Motivation in Tegal City, Indonesia." Management Science Letters 10 (1): 235-246.

16. Haseeb, M., Hussain, H., Slusarczyk, B., \& Jermsittiparsert, K. 2019. "Industry 4.0: A Solution towards Technology Challenges of Sustainable Business Performance." Social Sciences 8 (5): 184

17. Haseeb, M., Hussain, H., Kot, S., Androniceanu, A., \& Jermsittiparsert, K. 2019. "Role of Social and Technological Challenges in Achieving a Sustainable Competitive Advantage and Sustainable Business Performance." Sustainability 11 (14): 3811

18. Haseeb, M., Kot, S., Hussain, H., \& Jermsittiparsert, K. 2019. "Impact of Economic Growth, Environmental Pollution, and Energy Consumption on Health Expenditure and R and D Expenditure of ASEAN Countries." Energies 12 (19): 3598.

19. Huda, S., Tsani, I., Syazali, M., Umam, R., \& Jermsittiparsert, K. 2020. "The Management of Educational System Using Three Law Auguste Comte: A Case of Islamic Schools.” Management Science Letters 10 (3) (In press), DOI: 10.5267/j.msl.2019.9.018.

20. Usak, M., Kubiatko, M., Shabbir, M., Dudnik, O., Jermsittiparsert, K., \& Rajabion, L. 2019. "Health Care Service Delivery Based on the Internet of Things: A Systematic and Comprehensive Study." International Journal of Communication Systems 32 (14): e4179.

21. Jermsittiparsert, K., Ambarita, D., Mihardjo, L., \& Ghani, E. 2019 "Risk-Return through Financial Ratios as Determinants of Stock Price: A Study from ASEAN Region.” Journal of Security and Sustainability Issues 9 (1): 199-210.

22. Maseleno, A., Hardaker, G., Sabani, N., \& Suhaili, N. (2016). Data on multicultural education and diagnostic information profiling: Culture learning styles and creativity. Data in brief, 9, 1048.

23. Maseleno, A., Huda, M., Jasmi, K. A., Basiron, B., Mustari, I., Don, A. G., \& bin Ahmad, R. (2019). Hau-Kashyap approach for student's level of expertise. Egyptian Informatics Journal, 20(1), 27-32.

24. Maseleno, A., Huda, M., Siregar, M., Ahmad, R., Hehsan, A., Haron, Z., ... \& Jasmi, K. A. (2017). Combining the previous measure of evidence to educational entrance examination. Journal of Artificial Intelligence, 10(3), 85-90.

25. Thabhiranrak, T. \& Jermsittiparsert, K. 2019. "Towards Sustainable Functioning of Organization: Women Empowernment and Corporate Management Culture." Journal of Security and Sustainability Issues 9 (1): 321-332.

26. Chienwattanasook, K. \& Jermsittiparsert, K. 2019. "Impact of Entrepreneur Education on Entrepreneurial Self-Employment: A Case Study from Thailand." Polish Journal of Management Studies 19 (1): 106-116.

27. Jermsittiparsert, K., Sutduean, J., Sriyakul, T., \& Khumboon, R. 2019. "The Role of Customer Responsiveness in Improving the External Performance of an Agile Supply Chain.” Polish Journal of Management Studies 19 (2): 206-217.

28. Jermsittiparsert, K., Sutduean, J., \& Sriyakul, T. 2019. "Effect of Service Innovation and Market Intelligence on Supply Chain Performance in Indonesian Fishing Industry." Industrial Engineering \& Management Systems 18 (3): 408-417.

29. Jermsittiparsert, K., Namdej, P., \& Somjai, S. 2019. "Green Supply Chain Practices and Sustainable Performance: Moderating Role of Total Quality Management Practices in Electronic Industry of Thailand." International Journal of Supply Chain Management 8 (3): 33-46.

30. Somjai, S. \& Jermsittiparsert, K. 2019. "The Trade-off between Cost and Environmental Performance in the Presence of Sustainable Supply Chain." International Journal of Supply Chain Management 8 (4) 237-247.

31. Jermsittiparsert, K. \& Sawasdee, A. 2012. "Formal Education for Non-Thai or Undocumented Person in Thailand amidst the Challenge of Nationalism and Transnationalism: A Case Study of Wat Sirimongkhol School, Samut Sakhon Province.” Kasetsart Journal - Social Sciences 33 (2): 203-213.

32. Holzinger, A.: Trends in interactive knowledge discovery for personalized medicine: cognitive science meetsmachine learning. IEEE Intell. Inform. Bull. 15, 6-14 (2014)

33. Huppertz, B., Holzinger, A.: Biobanks a source of large biological data sets: open problems and future challenges. In: Holzinger, A., Jurisica, I. (eds.) Knowledge Discovery and DataMining. LNCS, vol. 8401, pp. 317-330. Springer, Heidelberg (2014) 
34. Ghahramani, Z.: Probabilistic machine learning and artificial intelligence. Nature 521, 452-459 (2015)

35. Mayer, C., Bachler, M., Holzinger, A., Stein, P., Wassertheurer, S.: The effectof threshold values and weighting factors on the association between entropymeasures and mortality after myocardial infarction in the cardiac arrhythmiasuppression trial. Entropy 18, 1-15 (2016)

36. Jadad, A.R., OGrady, L.: How should health be defined? Br. Med. J. 337, a2900 (2008)

37. Parry, D.: Health informatics. In: Kasabov, N. (ed.) Springer Handbook of Bio-/Neuro-informatics, pp. 555-564. Springer, Heidelberg (2014)

38. Holzinger, A.: Interactive machine learning for health informatics: when do we need the human-in-the-loop? Brain Inform. (BRIN) 3, 119-131 (2016) 